\title{
Remote Sensing Contributions to Prediction and Risk Assessment of Natural Disasters Caused by Large Scale Rift Valley Fever Outbreaks
}

\author{
Assaf Anyamba, Kenneth J. Linthicum, Jennifer Small, Seth C. Britch, Compton J. Tucker.
}

\begin{abstract}
Remotely sensed vegetation measurements for the last 30 years combined with other climate data sets such as rainfall and sea surface temperatures have come to play an important role in the study of the ecology of arthropod-borne diseases. We show that epidemics and epizootics of previously unpredictable Rift Valley fever are directly influenced by large scale flooding associated with the El Niño/Southern Oscillation. This flooding affects the ecology of disease transmitting arthropod vectors through vegetation development and other bioclimatic factors. This information is now utilized to monitor, model, and map areas of potential Rift Valley fever outbreaks and is used as an early warning system for risk reduction of outbreaks to human and animal health, trade, and associated economic impacts. The continuation of such satellite measurements is critical to anticipating, preventing, and managing disease epidemics and epizootics and other climate-related disasters.
\end{abstract}

Index Terms-Climate variability, El Niño/Southern Oscillation, Rift Valley fever virus, Normalized Difference Vegetation Index, arthropod-borne virus, predictive model, risk management and mitigation.

Manuscript received September 21, 2011. This work was supported in part by the U.S. Department of Defense, Armed Forces Health Surveillance Center, Division of GEIS Operations, the U.S. Department of Agriculture, Agricultural Research Service and National Aeronautics and Space Administration. The work presented here is a summary of research results on remote sensing proxies from Rift Valley fever carried out by the group over the last 30 years.

A. Anyamba is with the Universities Space Research Association at NASA Goddard Space Flight Center, Greenbelt MD 20771 (corresponding author, phone: 301-314-6601; fax: 301-614-6699; e-mail: assaf.anyamba@nasa.gov).

K. J. Linthicum is with the USDA-ARS, Center for Medical, Agricultural, and Veterinary Entomology, Gainesville, FL 32608 (email: kenneth.linthicum@ars.usda.gov).

J. Small is with Science Systems Applications at NASA Goddard Space Flight Center, Greenbelt, MD 20771 (email: jennifer.l.small@nasa.gov).

S. C. Britch is with the USDA-ARS, Center for Medical, Agricultural, and Veterinary Entomology, Gainesville, FL 32608 (email:

seth.britch@ars.usda.gov)

C. J. Tucker is with the NASA Goddard Space Flight Center, Greenbelt MD 20771 (email: compton.j.tucker@nasa.gov)

\section{INTRODUCTION}

Remote sensing measurements of the biosphere are increasingly making major contributions to environmental and disaster risk mitigation strategies over the last 30 years. Measurements such as sea surface temperatures (SST), rainfall, and vegetation are enabling the study of biosphere dynamics as a truly coupled system. The ability to make these measurements globally and at fine temporal resolution from satellite platforms is providing insights into the drivers of insect disease vector populations and disease outbreak patterns. Catastrophic events in abiotic systems leading to natural disasters such as floods and breakdown of human infrastructure are routinely followed by massive events of communicable diseases [1]. However, patterns of extreme, anomalous change in global abiotic systems can also directly lead to emergence and spread of arthropod-borne diseases causing rapid and pervasive human morbidity and death, and economic disaster at national or sub-continental levels.

Climate variability and change is recognized as one of the major drivers contributing to the spread of arthropod-borne disease outbreaks [2]-[8]. Variations in the climate regime can lead to extreme temperatures, storm surges, flooding, or droughts which directly affect human health and impact the global, regional, and local ecology by producing conditions that precipitate disease epidemics. Extremes in climate affect populations of arthropod vectors that transmit disease. In particular, changes and variations in temperature may influence vector survival, susceptibility of vectors to pathogens, rates of vector population growth, phenology and seasonality of vector populations, replication and extrinsic incubation periods of viral pathogens in the vector, length and timing of transmission seasons, or vector population spatial distribution [2], [3]. Increases in precipitation may expand the size of mosquito larval habitats or create new habitats resulting in an overall increase in vector populations. Rainfall can also elevate humidity which increases the probability of vector survival [2]-[6]. Persistent and large scale drought conditions can change vector habitats by concentrating water into small pools, and increasing the proportion of container-breeding mosquito vectors around households. Extreme variations in temperature and precipitation also have impacts on the vertebrate hosts of disease vectoring insects. Increased rain 
can increase vegetation, food availability and host populations, while decreased rain can eliminate food resources forcing vectors and vertebrate hosts into human settlements thus increasing the probability of human contact [2]-[7].

One major indicator of climate extremes is the El Niño/Southern Oscillation (ENSO) index. Over the last 50 years, a number of studies have shown that climate variability associated with the ENSO phenomenon influences mosquitoborne human and animal disease outbreaks, most notably Rift Valley fever (RVF), Murray Valley encephalitis, chikungunya, and dengue [9]-[15] through large scale floods and droughts. The influence of ENSO on the global climate system, especially over the global tropics, through interannual variations in temperature, atmospheric circulation, and precipitation produce different anomaly patterns in the aforementioned climate variables with near-cyclical transitions from the warm (El Niño) phase to the cold (La Niña) phase.

In regions of ENSO teleconnections, theseis quasi-cyclical patterns lead patterns of drought and flood that may lead to a variety of natural disasters including those of public health relevance. Prominent ENSO-related anomaly patterns in climate variables are now known to be temporally and spatially associated with certain vector borne-disease outbreaks. RVF is a well-documented example of a vector-borne disease of significant public health and economic relevance that has been shown to be tightly coupled with the ENSO phenomenon [11].

\section{RIFT VALLEY FEVER}

$\mathrm{RVF}$ is a mosquito-borne viral hemorrhagic disease with pronounced health and economic impacts to domestic animals and humans in much of sub-Saharan Africa [16]. The virus is classified in the family Bunyaviridae and is a Phlebovirus, a genus of viruses primarily associated with mosquito and sand fly vectors. The range of RVF has extended beyond its established endemic range of sub-Saharan Africa into Egypt in 1977 [17] and emerged in Saudi Arabia and Yemen in 2000 [18] (Fig. 1). This evidence of RVF invasion into new regions creates a precedent for further globalization. The Rift Valley fever virus (RVFV) is thought to be maintained in an endemic cycle which depends upon intermittent heavy rainfall events and periodic short term flooding of low lying habitats, known as dambos or pans, and on the vertical transmission of the virus (i.e., transovarial inheritance of the virus from female mosquitoes to offspring) by floodwater Aedes mosquitoes (Fig. 2). Rift Valley fever epizootics/epidemics have occurred unpredictably until recently during exceptional years of abovenormal and prolonged rainfall (Fig. 3) which floods low lying areas. This sustained or repeated flooding favors hatching and survival of multiple, consecutive broods of virus-infected Aedes mosquito eggs. The most important known animal species in RVF epidemics are domestic ungulate livestock, especially sheep, cattle, and goats. Unfortunately, the potential role of mammalian wildlife as RVFV reservoirs or amplifying hosts is not sufficiently known. Infection of domestic animals is caused by probing or blood feeding by female Aedes mosquitoes possessing a disseminated RVFV infection. After infection, these livestock species suffer significant morbidity, mortality, and up to $100 \%$ abortion especially in sheep populations; and their high viremias are sufficient to infect other mosquitoes [17]. Later in the epizootic period, lingering floodwaters stagnate and subsequently produce vast populations of Culex species mosquitoes that serve as the primary horizontal vectors of RVFV between viremic domestic animals and humans. Many European, African, and North American mosquito species have been identified as potential competent vectors of RVFV [19], but much work remains to be done in this field.

In humans, infection with RVF produces fever, chills, and myalgia and normally resolves without further consequences after several days. In less than $3 \%$ of cases more severe disease occurs, including: retinal lesions (macular degeneration), hemorrhagic fever, or encephalitis. Human infections may be caused by the bite of an infected mosquito, consumption of or close contact with fluids or tissues of infected animals, or exposure to infectious aerosols. Humans may be protected from the insect pathway of infection by the diligent use of insect repellents, bed nets, and insect control measures. Vector control is a viable option, especially with the $_{60}$

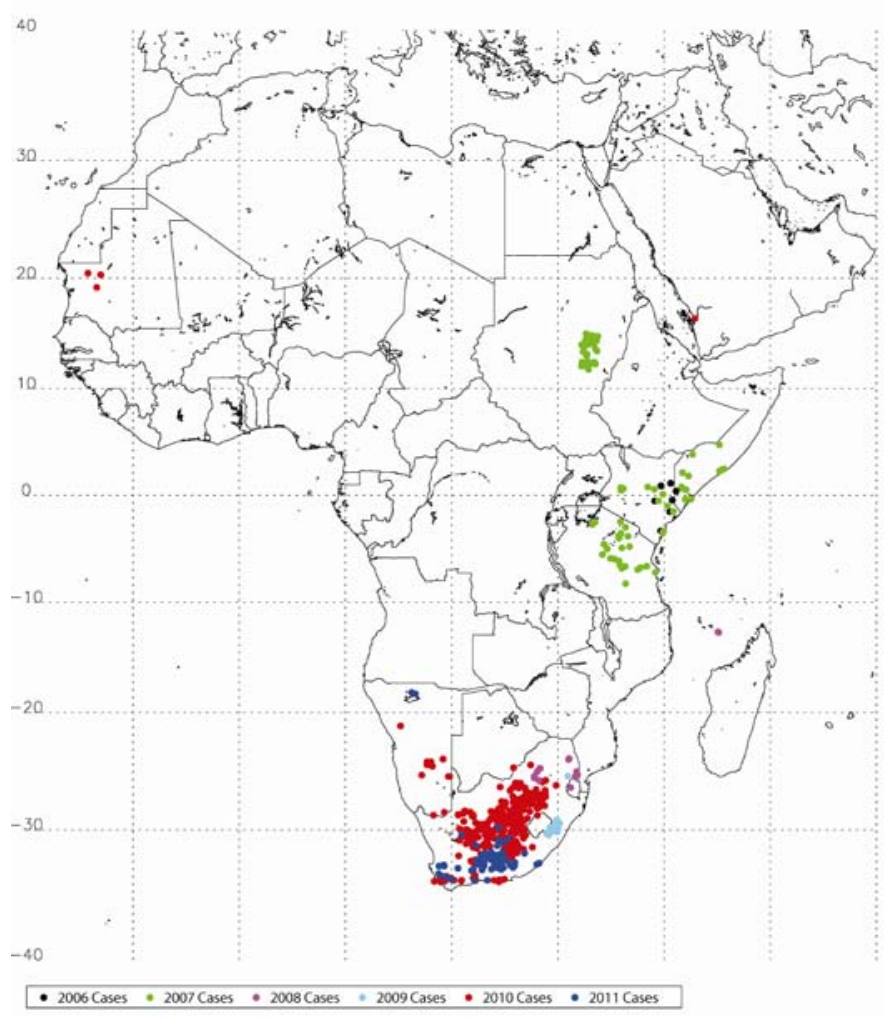

Fig. 1. Geographic distribution of recent (2006-2011) Rift Valley fever epidemics/epizootics.

recent development and operational use of accurate predictions of RVF epidemics/epizootics based on an innovative approach focusing on the specific habitats of immature floodwater Aedes mosquito reservoirs/vectors [20]. Human vaccination could prevent human disease in endemic areas; however, human vaccines still remain investigational and are only available in limited quantities involving a protracted series of inoculations 
and follow-up serology. Vaccination of domestic cattle, sheep, and goats could prevent or mitigate epizootic/epidemic transmission of RVFV since these ungulates most likely serve as the primary amplifying hosts of the virus. An optimum livestock vaccine would (1) protect vaccinated animals from disease, (2) not cause abortion, (3) produce antibodies that would be distinguishable from natural infection of the virus, and (4) not revert to virulence. Currently, both inactivated and live attenuated vaccines are available in endemic areas of subSaharan Africa, but are not ideal and new and more stable vaccines are under development.

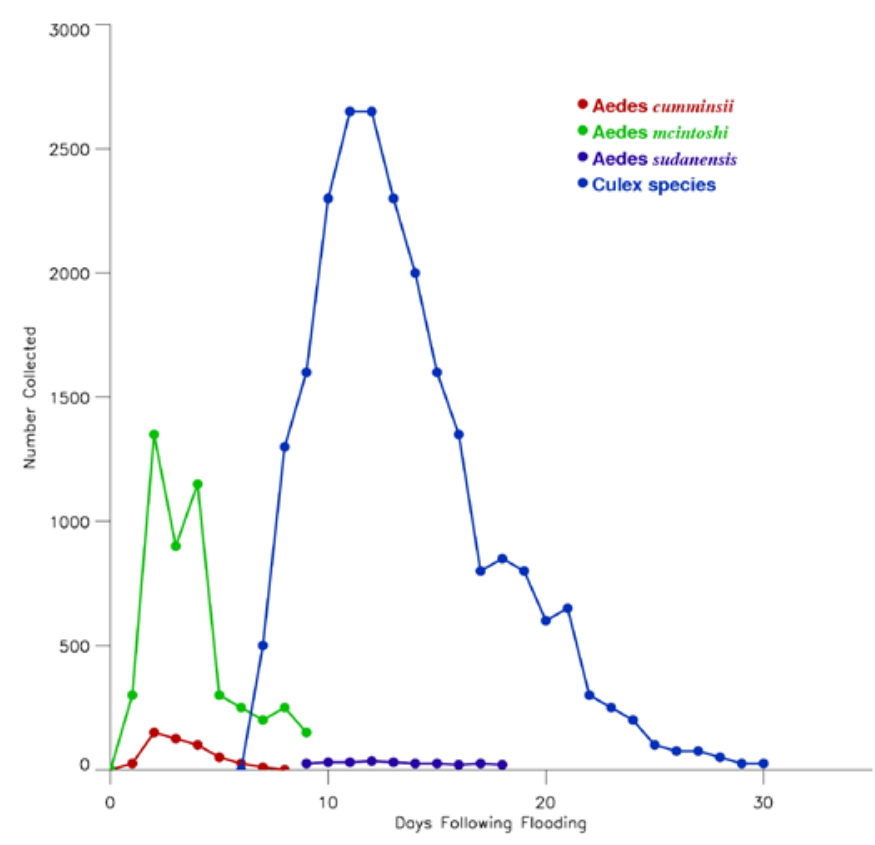

Fig. 2. Mosquito population succession dynamics after a flood event (Reconstructed after [34])

Episodic activity of RVF epizootics/epidemics over the last 35 years in Egypt, West Africa, Sudan, Madagascar, and the Arabian Peninsula has illustrated the importance of land-use, including irrigation and deforestation, in the continuing emergence of this virus as a major agricultural and human disease in sub-Saharan Africa, the Middle East, and the Arabian Peninsula. The increased frequency of the occurrence of both prolonged or intense RVF transmission in East Africa in 1997-1998 and 2006-2007, Sudan in 2007, South Africa in 2008-2011, and Madagascar in 2007-2008 has increased the serious potential for expansion of RVFV into a wide-range of suitable but immunologically naive areas such as the Middle East, the Mediterranean, and the Americas. The economic effect of the recent RVF outbreak in East Africa has been estimated at \$65 million [21] (Fig 4.). The economic impact on the United States or another non-endemic country would be substantial. Livestock feed suppliers, health care insurance, the food-service industry, and confidence in the food supply chain would certainly be impacted. For example, the United States had beef-related exports in 2003 of $\$ 5.7$ billion, and the Organization of Animal Health (OIE) imposes a 4 year trade ban on any country with confirmed RVF transmission [22].
The impacts an RVF epidemic/epizootic are up to now only estimates, but in totality are enormous given the costs to public health, economic impacts of international livestock trade bans on the affected countries, economic dislocations, and disruptions to the food supply chain. In essence, an RVF outbreak amplifies the initial disaster due to flooding.

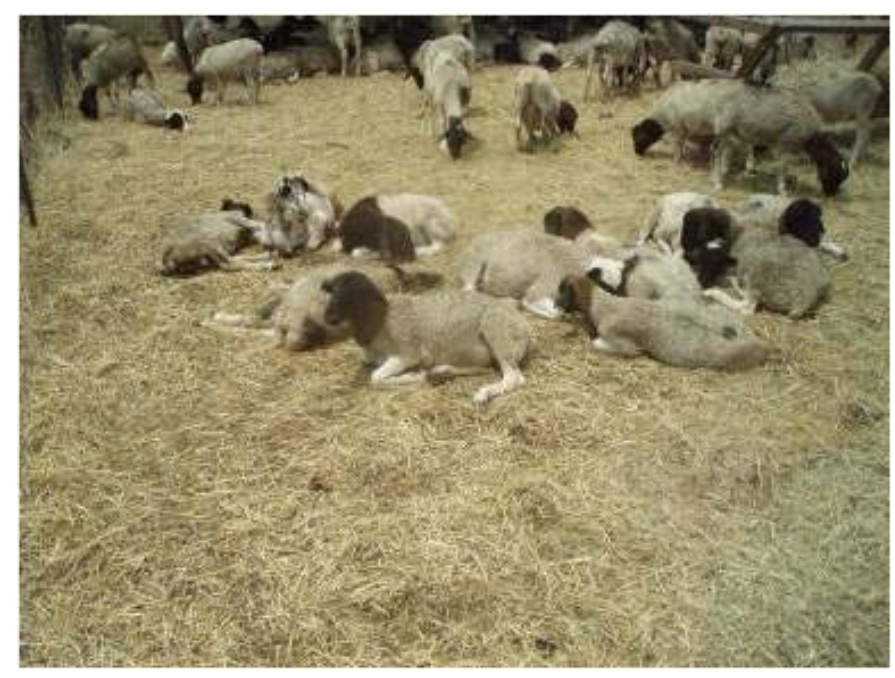

Fig. 4. Sheep that were permitted to graze new infected mosquito habitats on a farm in Kenya during the 2006-2007 outbreaks in the Horn of Africa leading to abortions and high mortality in the sheep population. Exotic breeds are particularly susceptible to Rift Valley fever infection, and young and adult sheep can die and pregnant ewes regularly abort.

\section{REMOTE SENSING OF VEGETATION}

Since the early 1980s, there have been attempts to use remote sensing data to identify ecological conditions associated with RVF outbreaks in East Africa [22]. Most of the data that have been used in such studies are from measurements made by the Advanced Very High-Resolution Radiometer (AVHRR) instrument aboard the National Oceanographic and Atmospheric Administration series of polar orbiting satellites. Measurements in the visible red and near infrared bands on this instrument are of specific relevance to ecology. Green plant tissue has a strong chlorophyll absorption in the red portion of the spectrum and a very high reflectance in the near infrared portion. This unique spectral response of vegetation makes it possible to differentiate vegetation from other surface materials remotely. The normalized difference vegetation index (NDVI) is derived from these spectral measurements in the form:

$$
\text { NDVI }=\frac{\rho_{\text {nir }}-\rho_{\text {red }}}{\rho_{\text {nir }}+\rho_{\text {red }}}
$$

where $\rho_{\text {nir }}$ and $\rho_{\text {red }}$ are the surface reflectances in the near infrared and red portions of the electromagnetic spectrum, respectively [23]. Derived NDVI values range between -1 and +1 NDVI units, with values $<0$ indicating absence of vegetation and values $>0$ showing increasing amounts of green vegetation. This index provides a robust measure of the presence and abundance of vegetation in a wide range of 
environmental conditions [24]. The NDVI has been found to be very useful in monitoring rainfall dynamics in semi-arid and arid areas where grasslands and savanna bushlands are the dominant vegetation types [25], [26], primarily because semiarid vegetation is very sensitive to variations in precipitation. For example, comparative data show an approximate linear relationship between NDVI and precipitation in a range of semi-arid lands of Africa (Fig. 5) [27], [28]. Precipitation and green vegetation dynamics are a major determinant of life cycles of animals and insects in semi-arid lands in many parts of the world. Close relationships have been found between the seasonal trace of green vegetation development, as measured by NDVI, and breeding and upsurge patterns of particular insects, such as locusts and mosquitoes [29]-[33]. Widespread heavy rains result in rapid vegetation development that provides ideal habitat for immature and adult mosquito vector populations to increase and thrive, significantly elevating the risk of RVF outbreaks [34], [35].
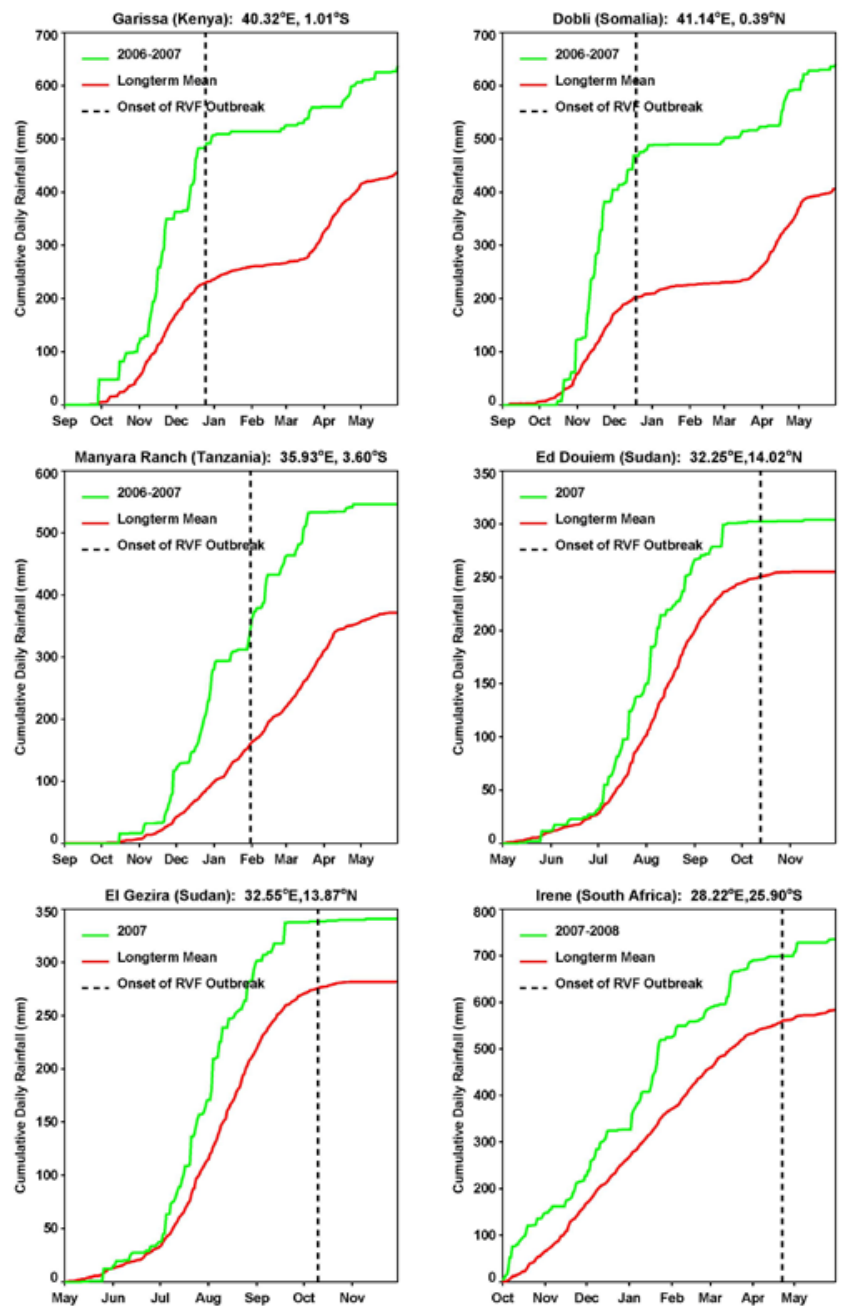

Fig. 3. Cumulative daily rainfall (green lines) profiles for periods of Rift Valley fever activity and mean long-term cumulative daily rainfall (red lines) for sites with reported Rift Valley fever activity. Dotted line represents when the first case of Rift Valley fever was identified at each location. Each of the outbreak locations was preceded by above-normal rainfall for 3-4 months (Adapted from [54]).

\section{Climatic CONTEXt OF RVF OUtBreak PATterns}

Rainfall in semi-arid lands of Africa ranges between $\approx 200$ $800 \mathrm{~mm} / \mathrm{yr}$. and exhibits large interannual variability, on the order of $\geq 20-30 \%$ of the average annual value [36], [37]. Characteristics of rainfall variability patterns have been examined [38]-[40], and there is a tendency for persistence of drought or above-normal rainfall periods with marked biennial characteristics over East Africa and Southern Africa [41]. Given the nearly linear relationship between rainfall and NDVI, the index may be used to examine land surface patterns and impacts of drought or above normal rainfall over space and time in areas with limited or no rain gauge measurements. At the interannual time scale, the cycling between wet and dry years has been linked to the ENSO climate phenomenon that

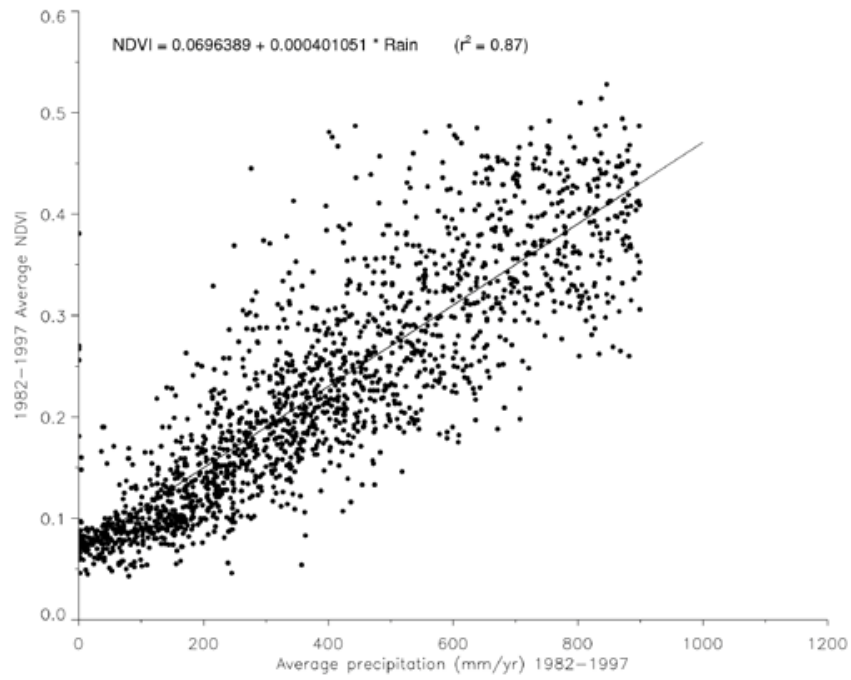

Fig. 5. Comparison between average precipitation from 1982 to 1987 for 1,794 stations from West Africa and coincident normalized difference vegetation index.

results from the changes in SST in the equatorial Pacific Ocean [42]-[44]. The occurrence of a warm (El Niño) or cold (La Niña) phase of ENSO leads to large-scale shifts in precipitation patterns across the global tropics and a consequent increase in both pathogen and vector abundance [11]. Over Africa, there is a tendency for drought (wet) conditions over Southern Africa during El Niño (La Niña) periods and the reverse conditions over East Africa [40]. The signal of ENSO in vegetation has been detected by examining NDVI time series for Africa and elsewhere [45]-[47]. Given the spatially continuous nature of these data sets, the anomalous vegetation conditions resulting from ENSO-linked precipitation variability can be mapped [48]. Previous research demonstrates clearly that interannual variability in rainfall, SST, and NDVI coincide with historical RVF outbreak patterns in Kenya [11]: more than 90\% of RVF outbreak events since 1950 have occurred during warm ENSO events resulting in above normal rainfall and flood in East Africa (Fig. 6). This is especially true when warm ENSO events coincide with warm events in the equatorial Western Indian Ocean (Fig. 7) [49]-[51]. The inter-epizootic period is dominated by La Niña events (the cold phase of ENSO), which 
results in drought in East Africa and wetter than normal conditions and floods in Southern Africa [41], [50]. Recent evidence shows that RVF outbreaks in Southern Africa are coupled to La Niña patterns [20]. Interannual climatic variability, in part driven by ENSO events with differential impacts on rainfall anomaly patterns on Eastern and Southern Africa, largely influences the temporal patterns of RVF outbreaks.

\section{MAPPING RVF RISK}

On the basis of this previous research [11], [16], [19], [29][32], [34], [35] we have developed a monitoring and risk mapping system that utilizes the NDVI as a proxy for ecological dynamics to map areas at potential risk of Rift Valley fever.

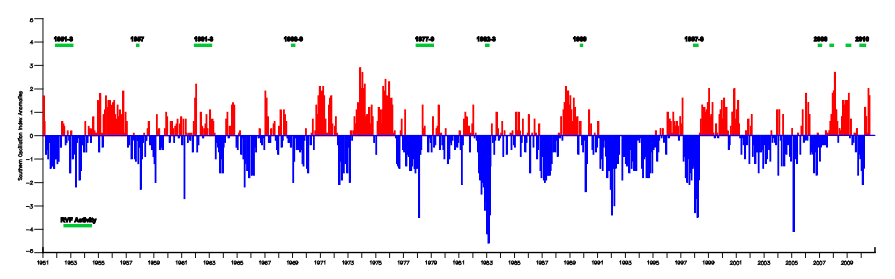

Fig. 6. Rift Valley fever outbreak events plotted against time and the Southern Oscillation Index (SOI), a measure of the phase of El Niño/Southern Oscillation events. Most RVF outbreak events have occurred during the warm phase of ENSO (shown in red; negative SOI index shown in blue). Reconstructed after [11] and updated.

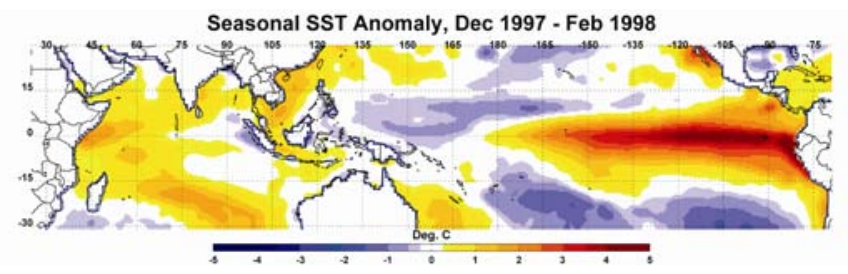

Fig. 7. Global seasonal equatorial sea surface temperature anomalies during the peak of the El Niño event December, 2006-January, 2007 associated with the Rift Valley fever outbreak in East Africa.

This is based on the assumption that NDVI is an integrator of a complex set of habitat variables, including for example rainfall, temperature, soil/water quality, refugia, and insolation, which are important for the emergence, survival, and propagation of Rift Valley fever mosquito vectors. In the first element of the system we examine NDVI anomalies to detect areas of persistent greenness using, typically, a threemonth moving window with the formula:

$\overline{N D V I}_{\Delta(3 \text { mon })}=\frac{\sum_{i=t}^{t-2} N D V I_{\Delta i}}{3}$

where $\overline{N D V I_{\Delta}(3 m o n)}$ is the average NDVI anomaly over the previous three months (i.e., t, the current month, and t- 1 and $\mathrm{t}-$ 2, the two previous months), and where $\overline{\operatorname{NDVI}_{\Delta}(3 m o n)}>0.1$. That is, persistently positive anomalies must have a threemonth mean NDVI anomaly exceeding a threshold of 0.1 NDVI units. All three months input must also have anomalies greater than +0.025 NDVI units. The value of +0.025 is computed from long-term AVHRR NDVI data and represents variability over stable desert areas that have a historical variation of $+/-0.025$. We therefore consider any variation greater or less than these values of real significance to ecological and vector population dynamics [52]. In the second element of the system we generate a mask that incorporates areas of historical outbreaks [11], [16], [17] and areas that show high interannual variability signals from the standpoint of both rainfall and NDVI [27], [37]-[41], [46]-[48]. The mask is used to constrain the analysis to areas of potential epidemics/epizootics. Areas of persistent positive NDVI anomalies are mapped only over these areas and indicate areas at risk for RVF, i.e., ideal for RVF vectors to emerge and multiply. In addition the areas at risk are constrained by areas of livestock (as amplifying hosts) and human population,

The system retrospectively predicted areas where Rift Valley fever outbreaks occurred between 1981 and 1998 [52] and subsequently predicted areas of recent Rift Valley fever outbreaks in East Africa (2006-2007), Sudan (2007) and Southern Africa (2008-2011). All three of these regions had persistent above-normal rainfall (200-500 mm) and 2-4 months of $40-100 \%$ positive NDVI anomalies, which triggered risk alerts in the system months before RVFV activity was reported (Figs. 8 and 9) [9], [20]. The prolonged excess rainfall and resultant rapid green-up of vegetation created ideal conditions for hatching and survival of RVFV-infected mosquitoes, which rapidly increased vector mosquito populations leading to subsequent widespread infection of livestock and human populations. Overall, for East Africa the early warning information provided in 2006 enabled country preparedness and early detection and response activities to be undertaken $\sim 2$ months earlier compared with the previous epidemic/epizootic of 1997-1998. Elsewhere various efforts including vaccination of livestock, vector control, and mass mobilization were implemented to minimize impacts of the epizootics/epidemics.

\section{CONCLUSION}

We have demonstrated the application of satellite-derived coarse resolution vegetation index time series in studying the ecological dynamics associated with Rift Valley fever outbreaks resulting from flooding on a large scale. The importance of having such temporal information on a continuous basis allows for monitoring fluxes in the environment that have critical influence of disease vectors. Such information can be used with other satellite and terrestrial measurements to create models that can be used in risk mapping and prediction. Ultimately the importance of this work is to prevent or minimize impacts of outbreaks on trade economy by providing decision makers with information to structure early warning response protocols and messages. Conditions for outbreaks and spread of vector-borne diseases are created as the climate system exhibits more extreme variability. Satellite remote sensing is an important source of data to study such extreme conditions and to provide early warning and risk information for various health and other natural disasters. The classification of RVF epidemics or epizootics as natural disasters directly linked to extreme global climate anomalies cannot be overstated. The RVF outbreak of 
1951 in South Africa led to approximately 20,000 human infections; the outbreak of 1977-78 in Egypt led to 18,000 human infections, including 598 deaths; the 1997-1998 outbreak across 5 countries in the Horn of Africa led to over 90,000 human infections, the loss of more than 100,000 domestic animals, and a costly ban on livestock exports; and the 2006-2007 RVF outbreak across Somalia, Kenya, and Tanzania led to over 1000 reported human cases, including over 300 deaths, in addition to the economic impacts described above [9], [53].

While progress has been made in prediction and risk mapping of RVF, a number of outstanding issues remain. Currently, the model uses NDVI as the primary data input as a proxy for both ecological dynamics and rainfall. The explicit incorporation of real-time rainfall in the model can enable the improvement of the risk mapping through a ranking of risk based on accumulated rainfall as a measure of potential flood conditions (Fig. 3). Secondly, the current RVF epizootic area mask is based on a RVF literature survey to identify countries where there have been episodes of RVF activity adjusted by coarse-scale long-term rainfall and NDVI to identify areas of pronounced interannual variability. This however does not take into consideration patterns of land cover/land use change that may create or destroy mosquito habitats thus changing risk characterization at local level. This may have been the reason for model failure in identifying risk in RVF outbreaks along coastal Kenya in 2006-2007, in South Africa (January February 2008), in Sudan within the Gezira irrigation scheme, and some areas in Madagascar. Better land cover characterization using more fine-scale resolution data such as LANDSAT-based Africover classification can tremendously improve the identification of potential RVF epizootic/epidemic areas across all countries at risk. These are two important areas that remote sensing can make a contribution to in model refinement and improvement.

Finally, it is important to note that although the AVHRR instrument was originally designed solely for meteorological applications, significant and unintended uses for these data have included analyses of vegetation phenology, broad land cover mapping, and applications in mitigation of natural disasters associated with drought and flooding through the development of various national and international monitoring and early warning systems including those for vector-borne diseases.

In the short-term, there will be continued availability of NDVI data from the NOAA series of satellites (NOAA-18 and NOAA-19) and the Meteorological Operational polar-orbiting satellite (MetOp) AVHRR series from the European community that also fly AVHRR instruments. In addition, the availability of data since 2001 from MODIS has ensured that there is a redundancy in NDVI data availability for various disaster applications. The follow-on satellites in the Joint Polar Satellite System (JPSS) with the Visible/Infrared Imager Radiometer Suite (VIIRS) instruments (scheduled to launch in October, 2011) will guarantee that the history of coarse- to medium-scale global remote sensing data will continue to be available to support operational disaster early warning efforts. Such applications show the downstream societal value of investments by space agencies in remote sensing satellite platforms.

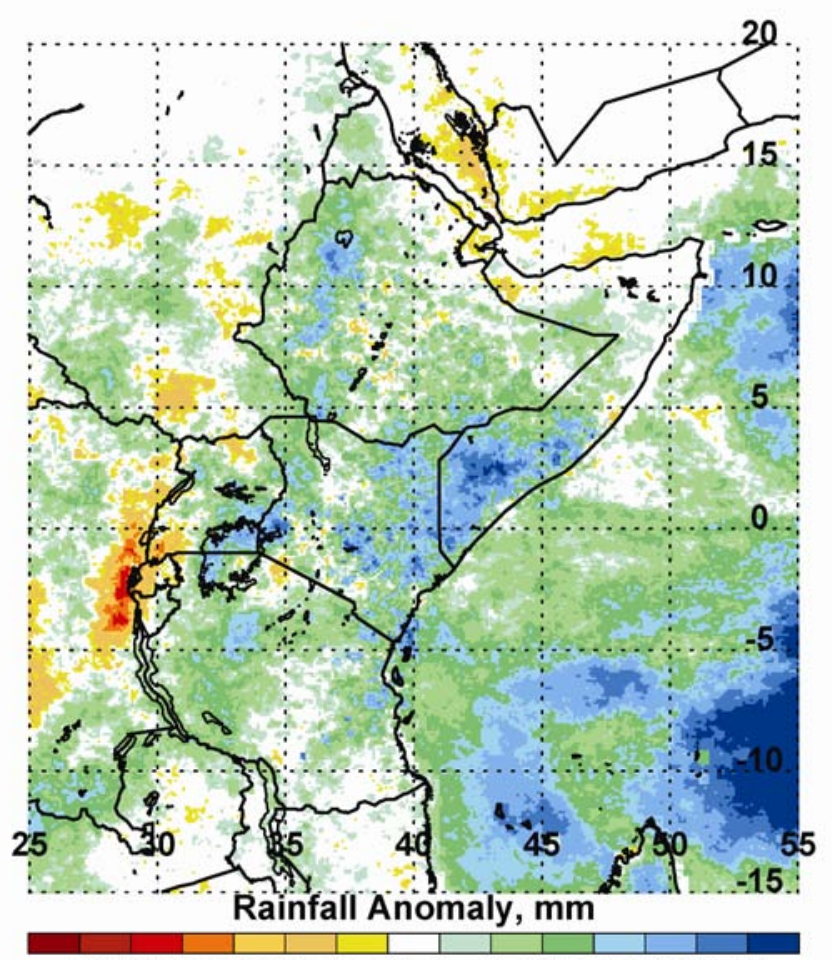

$-400-300-200-150-100-50 \quad-252550100150200300400$

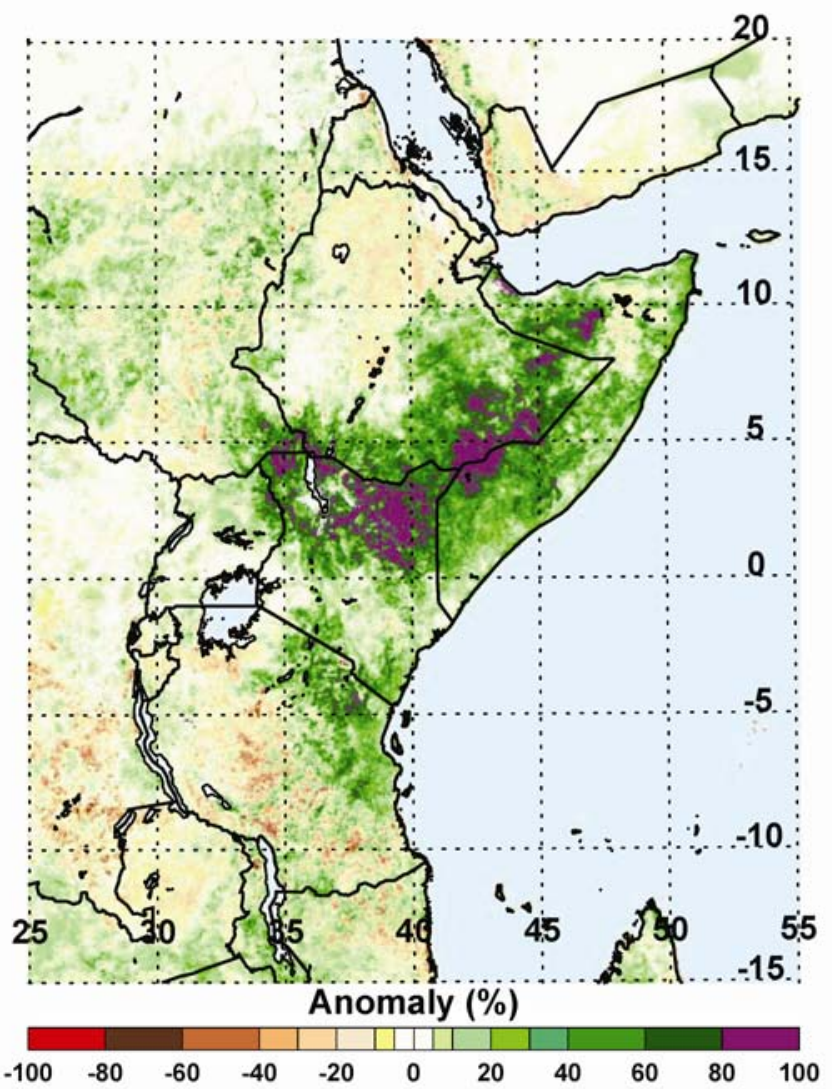

Fig. 8. Cumulative rainfall anomalies preceding outbreaks of Rift Valley fever in East Africa: September-December, 2006. The outbreaks were preceded by persistent and above-normal rain on the order of +200 to $+400 \mathrm{~mm}$ for a period of $\sim 2-4$ months (A-top). This resulted in anomalous green-up of vegetation (B-bottom), creating ideal ecological conditions for the production 
of Aedes and Culex mosquito vectors that transmit Rift Valley fever virus to domestic animals and humans (Adapted from [9])
A

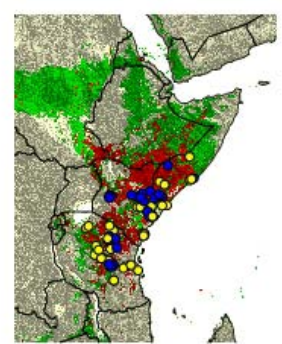

C

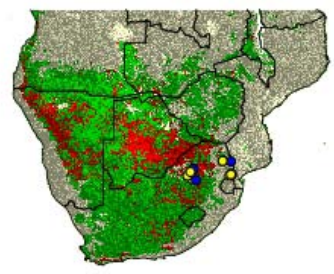

RVF risk areas

RVF potential epizootic areas
B

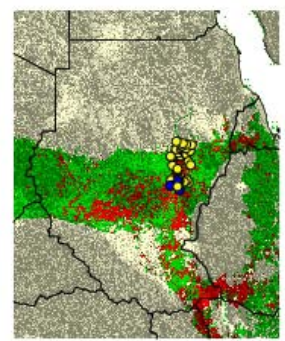

D

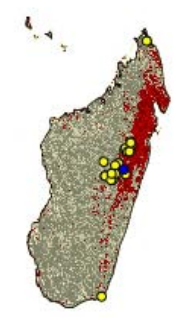

O Identitified as Non-Risk

- Identitified as Risk
Fig. 9. Aggregate Rift Valley fever risk maps for Eastern Africa: September, 2006-May, 2007(A) Sudan: May to October 2007(B), Southern Africa: October 2007-April 2008 (C) and Madagascar: October 2007 to April 2008 (D). Areas shown in green represent RVF potential epizootic areas; areas shown in red represent pixels that were mapped by the prediction system to be at risk for RVF activity during the respective time periods; blue dots indicate human cases identified to be in the RVF risk areas; and yellow dots represent human cases in areas not mapped to be at risk (Adapted from [20]).

\section{REFERENCES}

[1] World Health Organization Programme on Disease Control in Humanitarian Emergencies, Communicable Diseases Cluster, "Communicable diseases following natural disasters. Risk assessments and priority interventions,” WHO/CDS/NTD/DCE/ 2006.4

[2] D. J. Gubler, P. Reiter, K. L. Ebi, W. Yap, R. Nasci, and J. A. Patz, "Climate variability and change in the United States: potential impacts on vector- and rodent-borne disease," Environ. Health Perspect., vol. 109(S2), pp. 223-233, 2001.

[3] P. R. Epstein, "Climate change and human health," N. Engl. J. Med., vol. 353, pp. 1433-1436, 2005.

[4] M. J. Turell, M. O'Guinn, D. J. Dohm, and J. W. Jones, "Vector competence of North American mosquitoes (Diptera: Culicidae) for West Nile virus,” J. Med. Entomol., vol. 38, pp. 130-134, 2001.

[5] G. E. Glass, J. E. Cheek, J. A. Patz, T. M. Shields, T. J. Doyle, D. A. Thoroughman, D. K. Hunt, R. E. Enscore, K. L. Gage, C. Irland, C. J. Peters, and R. Bryan, "Using remotely sensed data to identify areas of risk for hantavirus pulmonary syndrome," Emerg. Infect. Dis., vol. 63, pp. 238-247, 2000.

[6] W. K. Reisen, R. P. Meyer, S. B. Presser, and J. L. Hardy, "Effect of temperature on the transmission of Western equine encephalomyelitis and St. Louis encephalitis viruses by Culex tarsalis (Diptera, Culicidae)," J. Med. Entomol., vol. 30, pp. 151160, 1993.

[7] G. Zhou, N. Minakawa, A. K. Githeko, and G. Y. Yan, “Association between climate variability and malaria epidemics in the East
African highlands,” Proc. Natl. Acad. Sci. U S A, vol. 101, pp. 2375-2380, 2004.

[8] J. A. Patz, T. K. Graczyk, N. Geller, and A. Y. Vittor, "Effects of environmental change on emerging parasitic diseases," Int. J. Parasitol., vol. 30, pp. 1395-1405, 2000.

[9] A. Anyamba, J.-P. Chretien, J. Small, C. J. Tucker, P. B. Formenty, J. H. Richardson, S. C. Britch, D. C. Schnabel, R. L. Ericson, and K. J. Linthicum, "Prediction of a Rift Valley fever outbreak," Proc. Natl. Acad. Sci. U S A, vol. 106, pp. 955-959, 2009.

[10] J.-P. Chretien, A. Anyamba, S. A. Bedno, R. F. Breiman, R. Sang, K. Sergon, A. M. Powers, C. O. Onyango, J. Small, C. J. Tucker, and K. J. Linthicum, "Drought-associated chikungunya emergence along coastal East Africa,” Am. J. Trop. Med. Hyg., vol. 76, pp. 405-407, 2007.

[11] K. J. Linthicum, A. Anyamba, C. J. Tucker, P. W. Kelley, M. F. Myers, and C. J. Peters, "Climate and satellite indicators to forecast Rift Valley fever epidemics in Kenya,” Science, vol. 285, pp. 397-400, 1999.

[12] N. A. Nicholls, "A method for predicting Murray Valley encephalitis in southeast Australia using the Southern Oscillation," Aust. J. Exp. Biol. Med. Sci., vol. 64, pp. 587-594, 1986.

[13] M. J. Bouma and C. Dye, "Cycles of malaria associated with El Niño in Venezuela,” J. Am. Med. Assoc., vol. 278, pp. 1772-1774, 1997.

[14] R. S. Kovats, M. J. Bouma, S. Hajat, E. Worrall, and A. Haines, "El Niño and health," Lancet, vol. 362, pp. 1481-1489, 2003.

[15] D. M. Engelthaler, D. G. Mosley, J. E. Cheek, C. E. Levy, K. K. Komatsu, P. Ettestad, T. Davis, D. T. Tanda, L. Miller, J. W. Frampton, R. Porter, and R. T. Bryan, "Climatic and environmental patterns associated with hantavirus pulmonary syndrome, Four Corners region, United States," Emerg. Infect. Dis., vol. 5, pp. 87-94, 1999.

[16] J. M. Megan and C. L. Bailey, "Rift Valley fever," in The Arboviruses: Epidemiology and Ecology, vol. 4, T. P. Monath, Ed. Boca Raton, FL: CRC Press Inc., 1989, pp. 51-76.

[17] C. J. Peters and K. J. Linthicum, "Rift Valley fever," in Handbook of Zoonoses. $2^{\text {nd }}$ ed. Section B: Viral, G. B. Beran, Ed., Boca Raton, FL: CRC Press, Inc., 1994, pp. 125-138.

[18] Centers for Disease Control and Prevention, "Outbreak of Rift Valley fever-Saudi Arabia, August-October,” Morb. Mortal. Wkly. Rep., vol. 49, pp. 905-908, 2000.

[19] K. J. Linthicum, F. G. Davies, A. Kairo, and C. L. Bailey, "Rift Valley fever virus (family Bunyaviridae, genus Phlebovirus). Isolations from diptera collected during an inter-epizootic period in Kenya,” J. Hyg., vol. 95, pp. 197-209, 1985.

[20] A. Anyamba, K. J. Linthicum, J. Small, S. C. Britch, E. Pak, S. de La Rocque, P. Formenty, A. W. Hightower, R. F. Breiman. J.-P. Chretien, C. J. Tucker, D. Schnabel, R. Sang, K. Haagsma, M. Latham, H. B. Lewandowski, S. Osman Magdi, M. Ally Mohamed, P. M. Nguku, J.-M. Reynes, and R. Swanepoel, "Prediction, assessment of the Rift Valley fever activity in East and Southern Africa 2006-2008 and possible vector control strategies.” Am. J. Trop. Med. Hyg., vol. 83(S2), pp. 43-51, 2010.

[21] P. D. Little, "Hidden Value on the Hoof: Cross-Border livestock Trade in eastern Africa," Common Market for Eastern and Southern Africa Comprehensive African Agriculture Development Program, Policy Brief Number 2, 2009.

[22] K.J. Linthicum, A. Anyamba, S. C. Britch, J.-P. Chretien, R. L. Erickson, J. Small, C. J. Tucker, K. E. Bennett, R. T. Mayer, E. T. Schmidtmann, T. G. Andreadis, J. F. Anderson, W. C. Wilson, J. Freier, A. James, R. Miller, B. S. Drolet, S. Miller, C. Tedrow, C. Bailey, D. A. Strickman, D. R. Barnard, G. G. Clark, and L. Zou,”A Rift Valley fever risk surveillance system for Africa using remotely sensed data: potential for use on other continents," Veterinaria Italiana, vol. 43, pp. 663-674, 2007.

[23] C. J. Tucker, "Red and photographic infrared linear combinations for monitoring vegetation,” Rem. Sens. Environ., vol. 8, pp. 127150, 1979.

[24] S. D. Prince, "Satellite remote-sensing of primary production comparison of results for Sahelian grasslands 1981-1988," Int. J. Rem. Sensing, vol. 12, pp. 1301-1311, 1991.

[25] P. H. Y. Hiernaux and C. O. Justice, "Follow-up of vegetal 
development during the summer of 1984 in the Mali Sahel," Int. J. Rem. Sensing, vol. 7, pp. 1515-1531, 1986.

[26] S. D. Prince and C. J. Tucker, "Satellite remote-sensing of rangelands in Botswana. 2. NOAA AVHRR and herbaceous vegetation," Int. J. Rem. Sensing, vol. 7, pp. 1555-1570, 1986.

[27] S. E. Nicholson, M. L. Davenport, and A. R. Malo, "A comparison of the vegetation response to rainfall in the Sahel and East Africa, using normalized difference vegetation index from NOAA AVHRR," Climatic Change, vol. 17, pp. 209-241, 1990.

[28] C. J. Tucker, H. E. Dregne, and W. W. Newcomb, "Expansion and contraction of the Sahara Desert from 1980 to 1990," Science, vol. 253, pp. 299-301, 1991.

[29] C. J. Tucker, J. U. Hielkema, and J. Roffey, "The potential of satellite remote-sensing of ecological conditions for survey and forecasting desert locust activity," Int. J. Rem. Sensing, vol. 6, pp. 127-138, 1985

[30] J. U. Hielkema, J. Roffey, and C. J. Tucker, "Assessment of ecological conditions associated with the 1980/81 desert locust plague upsurge in West Africa using environmental satellite data," Int. J. Rem. Sensing, vol. 7, pp. 1609-1622, 1986.

[31] K. J. Linthicum, C. L. Bailey, F. G. Davies, and C. J. Tucker, "Detection of Rift Valley fever viral activity in Kenya by satellite remote-sensing imagery," Science, vol. 235, pp. 1656-1659, 1987.

[32] K. J. Linthicum, C. L. Bailey, C. J. Tucker, K. D. Mitchell, T. M. Logan, F. G. Davies, C. W. Kamau, P. C. Thande, and J. N. Wagateh, "Application of polar-orbiting, meteorological satellite data to detect flooding of Rift Valley fever virus vector mosquito habitats in Kenya," Med. Vet. Entomol., vol. 4, pp. 433-438, 1990.

[33] S. I. Hay, J. A. Omumbo, M. H. Craig, and R. W. Snow, "Earth observation, geographic information systems and Plasmodium falciparum malaria in sub-Saharan Africa," Adv. Parasit., vol. 47, pp. 173-215, 2000.

[34] K. J. Linthicum, F. G. Davies, C. L. Bailey, and A. Kairo, "Mosquito species succession in a dambo in an East African forest," Mosquito News, vol. 43, pp. 464-470, 1983.

[35] K. J. Linthicum, F. G. Davies, C. L. Bailey, and A. Kairo, "Mosquito species encountered in a flooded grassland dambo in Kenya," Mosquito News, vol. 44, pp. 228-232, 1984.

[36] E. M. Rasmusson, "Global climate change and variability: effects on drought and desertification in Africa," in Drought and Hunger in Africa, G. H. Glantz, Ed. New York: Cambridge University Press, 1988, pp. 4-36.

[37] J. E. Janowiak, "An investigation of interannual rainfall variability in Africa," J. Climate, vol. 1, pp. 240-255, 1988.

[38] S. E. Nicholson, "The nature of rainfall fluctuations in sub-tropical West Africa," Monthly Weather Review, vol. 108, pp. 473-487, 1980.

[39] S. E. Nicholson, "Sub-Saharan rainfall in the years 1976-80 evidence of continued drought," Monthly Weather Review, vol. 111, pp. 1646-1654, 1983.

[40] S. E. Nicholson, "The spatial coherence of African rainfall anomalies - interhemispheric teleconnections," J. Climate Appl. Meteorol., vol. 25, pp. 1365-1381, 1986.

[41] S. E. Nicholson and D. Entekhabi, "The quasi-periodic behavior of rainfall variability in Africa and its relationship to the Southern Oscillation," Arch. Meteorol. Geophys.Bioclimatol. Ser. AMeteorol. Atmos. Phys., vol. 34, pp. 311-348, 1986.

[42] M. A. Cane, "Oceanographic events during El Nino," Science, vol. 222, pp. 1189-1195, 1983.

[43] E. M. Rasmusson and J. M. Wallace, "Meteorological aspects of the El Nino/Southern Oscillation," Science, vol. 222, pp. 11951202, 1983.

[44] C. F. Ropelewski and M. S. Halpert, "Global and regional scale precipitation patterns associated with the El Nino/Southern Oscillation," Monthly Weather Review, vol. 115, pp. 1606-1626, 1987.

[45] J. R. Eastman and M. Fulk, "Long sequence time-series evaluation using standardized principal components," Photogramm. Eng. Rem. Sensing, vol. 59, pp. 991-996, 1993.

[46] R. B. Myneni, S. O. Los, and C. J. Tucker, "Satellite-based identification of linked vegetation index and sea surface temperature anomaly areas from 1982-1990 for Africa, Australia, and South America," Geophys. Res. Lett., vol. 23, pp. 729-732, 1996.

[47] A. Anyamba and J. R. Eastman, "Interannual variability of NDVI over Africa and its relation to El Nino/Southern Oscillation," Int. J. Rem. Sensing, vol. 17, pp. 2533-2548, 1996.

[48] A. Anyamba, C. J. Tucker, and J. R. Eastman, "NDVI anomaly patterns over Africa during the 1997/98 ENSO warm event," Int. J. Rem. Sensing, vol. 22, pp. 1847-1859, 2001.

[49] N. H. Saji, B. N. Goswami, P. N. Vinayachandran, and T. Yamagata, "A dipole mode in the tropical Indian Ocean," Nature, vol. 401, pp. 360-363, 1999.

[50] A. Anyamba, C. J. Tucker, and R. Mahoney, "From El Nino to La Nina: vegetation response patterns over East and Southern Africa during the 1997-2000 period," J. Climate, vol. 15, pp. 3096-3103, 2002.

[51] C. Birkett, R. Murtugudde, and T. Allan, "Indian Ocean climate event brings floods to East Africa's lakes and the Sudd Marsh," Geophys. Res. Lett., vol. 26, pp. 1031-1034, 1999.

[52] A. Anyamba, K. J. Linthicum, R. Mahoney, and C. J. Tucker, "Mapping potential risk of Rift Valley fever outbreaks in African savannas using vegetation index time series data," Photogramm. Eng. Rem. Sensing [special issue, "Remote Sensing and Human Health"], vol. 68, pp. 137-145, 2002.

[53] C. W. Woods, A. M. Karpati, T. Grein, et al., "An outbreak of Rift Valley fever in northeastern Kenya, 1997-98," Emerg. Infect. Dis., vol. 8, pp. 138-144, 2002.

[54] A. Anyamba., K. J. Linthicum, J. Small, et al. "Climate Teleconnections and Recent Patterns of Human and Animal Disease Outbreaks". PLoS Negl. Trop. Dis., 6(1):e1465.doi:10.1371/journal.pntd.0001465. http://www.plosntds.org/article/info:doi/10.1371/journal.pntd.000 1465, 2012. 